\title{
A TRIAL PROGRAM FOR SELECTION TO INFANTRY TRAINING BRIGADE COMPANY COMMAND
}

CONTENTS

Page

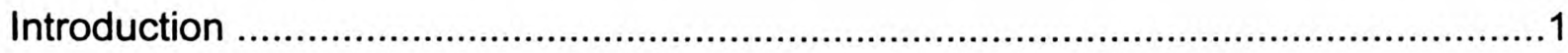

Phase I: Job Performance and Leadership ....................................

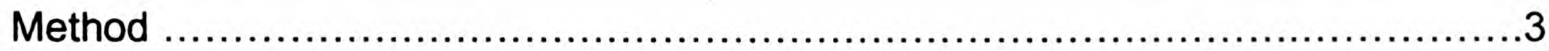

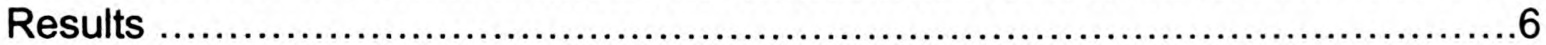

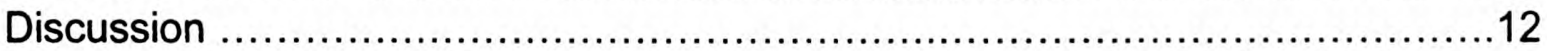

Phase II: Turbulence and Training Management..............................13

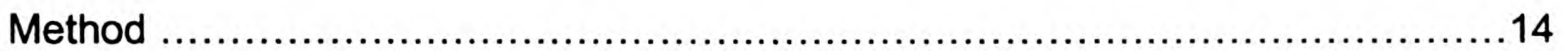

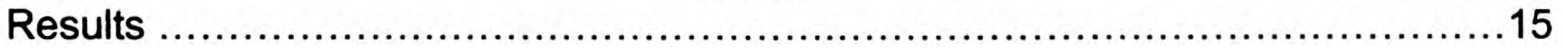

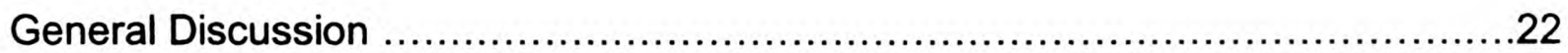

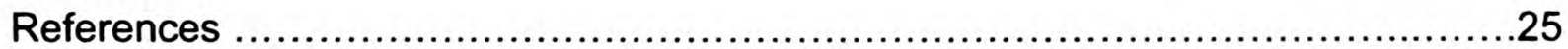

Appendix A: Previous Duty Positions Held and Army Schools Attended .............A-1

B: Phase I Surveys and Interview Instrument .........................

C: Number of Commanders Receiving "Top," "Middle," .................... and "Low" Agreement Ratings

D: Summary of Phase I Ratings of Company Commanders ..............

E: Goals for ITB and Expectations for Company Command...............

F: Phase II Surveys and Interview Instrument .......................

\section{LIST OF TABLES}

Table 1. Eight Subscales and Descriptive Traits for Phase I .5 Drill Sergeant, Battalion Commander, and Battalion CSM Surveys 